\section{Commentary: Propelling best-practice medicine into the 21st century}

\section{Matthew Pichert, MD, and Arnar Geirsson, MD}

Tenorio and colleagues ${ }^{1}$ provide an excellent analysis demonstrating promising results for the treatment of a complication that infrequently appears in any given single aortic practice. In this edition of the Journal, they present a retrospective analysis of a prospective multinational database consisting of 8 specialized aortic centers that characterizes the results of 29 patients undergoing fenestrated branched endovascular aortic repair of either visceral or intercostal artery aneurysms who have undergone past open abdominal aortic aneurysm repair. Despite a wide array of center-specific grafts/technologies used, their outcomes were excellent, where 30-day mortality was zero; however, freedom from reintervention at 2 years was $61 \%$. With patients having undergone abdominal aortic aneurysm repair living 15 to 20 years after initial treatment in trials such as EVAR 1 (Endovascular Aneurysm Repair 1), debate over best practice moves from initial intervention to reintervention. $^{2}$ An Achilles heel of evidence-based medicine has been the establishment of best practices for rare complications, with studies on reintervention delegated to highvolume single centers using data spanning decades. ${ }^{3}$ This leads to uncertainty as to generalizability to other specialized centers as well leaves the data vulnerable to comparing changing technologies and techniques over the study period.

Tenorio and colleagues navigated these challenges by using the Trans-Atlantic Aortic Research Consortium network of investigators, who are listed as collaborators. Through the combined efforts of all involved, Tenorio and colleagues managed to gather enough cases of patch

\footnotetext{
From the Division of Cardiac Surgery, Department of Surgery, Yale University School of Medicine, New Haven, Conn.

Disclosures: Dr Geirsson reported member, Medtronic Strategic Surgical Advisory Board. Dr Pichert reported no conflicts of interest.

The Journal policy requires editors and reviewers to disclose conflicts of interest and to decline handling or reviewing manuscripts for which they may have a conflict of interest. The editors and reviewers of this article have no conflicts of interest.

Received for publication April 15, 2021; revisions received April 15, 2021; accepted for publication April 15, 2021; available ahead of print April 27, 2021.

Address for reprints: Arnar Geirsson, MD, Division of Cardiac Surgery, Department of Surgery, Yale University School of Medicine, 330 Cedar St, Boardman 204, New Haven, CT 06519 (E-mail: arnar.geirsson@yale.edu).

J Thorac Cardiovasc Surg 2023;165:1272

$0022-5223 / \$ 36.00$

Copyright (c) 2021 by The American Association for Thoracic Surgery

https://doi.org/10.1016/j.jtcvs.2021.04.057
}

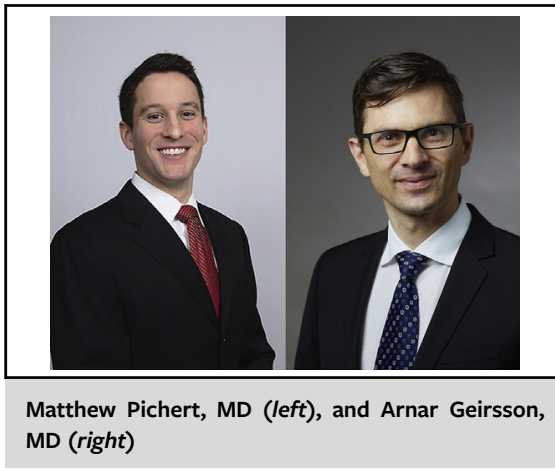

CENTRAL MESSAGE

Multicenter collaboration allows rare complications and resulting interventions to be studied like never before.

aneurysm repairs within a 10-year period to assume normality for statistical analysis. Of note, this analysis does not address generalizability to low-volume institutions, and the authors acknowledge treatment techniques evolved even within the 10-year period studied.

Nonetheless, the collaboration represents the future of data-driven best practices for rare complications, rare populations, and further patient stratification for common interventions. A rising issue in academic medicine from multicenter collaborations becomes data access, management, and authorship. With academic promotions based on first authorship, senior authorship, and so forth - a paper detailing best practices for a rare complication could leave a few primarily recognized for the work of many. While all authors here are appropriately thanked and recognized, academic medicine may need to adjust the current system to encourage and not discourage interinstitutional collaboration.

\section{References}

1. Tenorio ER, Oderrich GS, Schenzer A, Beck AW, Gargiulo M, Farber MA, et al. Endovascular repair of intercostal and visceral aortic patch aneurysm following open thoracoabdominal aortic aneurysm repair. J Thorac Cardiovasc Surg. 2023; 165:1261-71.e5.

2. Patel R, Sweeting MJ, Powell JT, Greenhalgh RM. Endovascular versus open repair of abdominal aortic aneurysm in 15-years' follow-up of the UK endovascular aneurysm repair trial 1 (EVAR trial 1): a randomised controlled trial. Lancet. 2016;388:2366-74

3. Bertoglio L, Mascia D, Cambiaghi T, Kahlberg A, Tshomba Y, Gomez JC, et al. Management of visceral aortic patch aneurysms after thoracoabdominal repair with open, hybrid, or endovascular approach. J Vasc Surg. 2018;67:1360-71. 